\title{
Martín Rivas: violencia mimética y pensamiento utópico*
}

Martín Rivas: mimetic violence and utopian thought

\author{
Edson Faúndez V., Fernando Ibáñez y María Luisa Martínez \\ Universidad de Concepción, Facultad de Artes y Humanidades, Instituto de Lenguas, Concepción, Chile. \\ Correo electrónico: efaundez@udec.cl,fibanezj@udec.cl, marmartinez@udec.cl
}

Este artículo examina, fundamentalmente, los efectos del deseo mimético y la emergencia de una ventana utópica en la novela Martín Rivas de Alberto Blest Gana.

Palabras clave: novela chilena, crítica literaria, deseo, utopía y mímesis.

This article examines, fundamentally, the effects of mimetic desire and the emergence of a utopian window in the novel Martín Rivas by Alberto Blest Gana.

Key words: Chilean novel, literary criticism, desire, utopia and mimesis.

\section{Blest Gana: realista del deseo}

José Miguel Oviedo advierte que en la escritura del llamado "padre de la novela chilena” domina una gradual progresión que va desde "un modelo casi puro de novela sentimental romántica -cuyo último ejemplo quizá sea El ideal de un calavera (1863) - a un tipo de novela que conjuga - con un sello muy personal- la intriga amorosa, el contexto histórico y la actitud de un realista social, que arranca con Martín Rivas (1862), se afirma en Durante la Reconquista y sigue hasta el final de su producción" (1997: 148). Como sostiene Guillermo Araya, "no hay, pues, etapas ni ciclos en la producción novelística de Blest Gana. Desde Una escena social (1853) hasta Gladys Fairfield (1912), el narrador tiene esencialmente los mismos medios expresivos y las obras presentan una orientación estética esencialmente igual" (1987: 165)². La

* Artículo escrito dentro del marco del proyecto DIUC-Ciencias Sociales (DIUC209.062.044-1FI), "Escritura, mal y utopía en las literaturas española y chilena de los siglos XIX, XX y XXI". Agradecemos el invaluable diálogo con Dieter Oelker, que nos permitió la posibilidad de considerar nuevas vías de orientación para este estudio. Asimismo, reconocemos el aporte de los anónimos evaluadores de este artículo.

1 Según Raúl Silva Castro, es Justo Arteaga Alemparte, en "Cuatro novelas de Alberto Blest Gana" (La Semana, N 14, 20-VIII-1859: 209-211), el primero en atribuir la paternidad de la novela chilena al autor de Martín Rivas.

2 La única excepción, según Araya, es Los transplantados, novela con “evidentes rasgos del naturalismo a lo Zola” (1987: 165) 
escritura del novelista que buscó "nacionalizar la literatura y establecer en el país la novela realista de costumbres, conforme al tipo de Balzac" (Alone 1940: 153), lo que puede considerarse "el primer signo de una novela regionalista americana" (Alegría 1978: 89), se caracteriza, entre otros aspectos, por "la constatación de su apego al hecho histórico, la minuciosa observación de las costumbres, la autenticidad de los retratos, su nacionalismo literario, su interés por novelar la historia del país y su visión crítica frente a las condiciones sociales de la época” (Román-Lagunas 1980: 605). El listado de los rasgos singularizadores de las ficciones realistas de Blest Gana debe incorporar, además, "el irreconciliable dilema entre el mundo ideal y el mundo material [y] el análisis de cómo se transforma la burguesía chilena y, a través de ella, la nación” (Oviedo 1997: 147), lo que envía a las proposiciones de Faletto y Kirkwood (1976) sobre las relaciones entre la sociedad burguesa y el liberalismo romántico visibles en la novelística de Blest Gana, a los planteamientos más recientes de Doris Sommer (1993) acerca de la significación de las alianzas amorosas singularizadoras de ficciones fundacionales como Martín Rivas y a las ideas de Juan Poblete sobre la significación de un "nuevo género de lectores (las mujeres y los sectores medios)" (2003: 51) en la consolidación del folletín y las novelas de costumbres: dispositivos ficcionales al servicio de "la construcción y homogenización de la nación" (2003: 51).

El retrato de la realidad social que se actualiza en las novelas de Blest Gana se despliega a partir de un minucioso estudio de la estructura y costumbres sociales, y de la producción de intrigas que, de alguna manera, posibilitan el examen detallado de personajes representativos de las "esferas sociales" estructurantes de la sociedad chilena, que está determinada, entre otros aspectos, por

la instalación de las condiciones económicas del capitalismo, [...] la lucha entre liberales y conservadores (aparente en muchos casos, pero nunca exenta por completo de repercusión para el afianzamiento político de la burguesía) y [...] el despliegue de una ideología también liberal, que se hará dominante en el nivel de la cultura y en las regiones del arte y de la producción literaria (Concha 1977: IX).

Las novelas de Blest Gana se convierten así en un archivo de la vida individual y social, que expone abiertamente los secretos de los personajes a partir de la adecuación nacional del estilo realista europeo, la crítica al materialismo dominante en la sociedad chilena, el rechazo de la imitación del romanticismo literario y la confianza en la función civilizadora de la literatura, como puede advertirse en el discurso "Literatura chilena. Algunas consideraciones sobre ella" (1861).

Pedro Balmaceda Toro señala en "La novela social contemporánea", artículo escrito en agosto de 1887, algunos rasgos del realismo al que sin duda adhiere Blest Gana, entre los que destacamos la preocupación por el detalle, la textualización de las pasiones encontradas y la visibilidad de las vidas miserables, silenciosas y oscuras del pueblo.

\footnotetext{
Muñoz y Oelker, en su Diccionario de movimientos y grupos literarios chilenos (1993), valoran los detalles otorgados por el autor respecto de la idea de realismo que pretende en sus novelas, destacando la influencia de escritores realistas contemporáneos (Balzac, Stendhal) y la importancia otorgada a la verosimilitud y la observación en el examen de la realidad social. No podemos olvidar los estudios de Cedomil Goič (1991), donde se destaca la integración de los problemas económicos y morales, así como la importancia de la sátira que contribuye a revelar los vicios que gobiernan la vida individual y colectiva.
} 
I es a la novela de hoy, a la novela realista, a quien deberá la historia el conocimiento, el detalle revelador, la cifra fisiolójica, las pasiones encontradas, la lucha, la agitación, las conmociones de la multitud, de la sociedad, tan desconocidas hasta aquí, i que, sin embargo, son los grandes factores de la vida de un pueblo, de sus cambios políticos i sociales, de sus conquistas i de sus esfuerzos de civilización i de progreso.

El pueblo tiene vida interior, vida miserable, actividad subterránea, que se desarrolla en el silencio i en la oscuridad, sin que ningun signo esterior lo revele, i son los novelistas quienes han bajado al fondo del pueblo, quienes han acercado la luz al foco de la miseria pintando sus depravaciones, ese organismo que ignorábamos por completo, que nos asombra, i que viene formándose con el despojo de todos los tiempos (1889: 205).

Balmaceda Toro considera que la materia que le concede densidad significativa a la novela realista se encuentra en la vida interior, miserable y subterránea del pueblo. La novela ilumina y visibiliza las zonas oscurecidas por el poder para presentar al lector las "depravaciones" y miserias humanas que proliferan en el subsuelo de las relaciones de poder.

Martín Rivas. Novela de costumbres político-sociales ${ }^{4}$ es un relato innovador y complejo para su tiempo, que destaca, según Raúl Silva Castro (1955), por construir una verdadera fotografía de la vida santiaguina. Los comentadores de la novela han estudiado fundamentalmente, desde diversos enfoques teóricos, metodológicos y disciplinarios, los procedimientos retóricos, la tematología, las influencias literarias y las relaciones que se establecen entre el texto, el contexto y los lectores. La dimensión deseante de la novela, específicamente el mimetismo que rige el despliegue del deseo, no ha sido analizada aún con suficiente rigor y profundidad. Los trabajos de Faletto y Kirkwood (1976), Doris Sommer (1993) y Juan Poblete (2003) son valiosos en este sentido y contribuyen de manera significativa a los propósitos de nuestra lectura.

El pensamiento antropológico-literario de René Girard orienta, en gran medida, nuestra reflexión ${ }^{5}$. El autor de Mentira romántica y verdad novelesca sostiene que el deseo humano es "realmente mimético, por lo que los textos que lo pintan como tal no pueden dejar de ser más 'fieles a la vida' que otros textos" (1984 11). La fidelidad a la vida, buscada por los escritores realistas y naturalistas del siglo XIX en Europa, radica, es cierto, en los operadores estilísticos de realidad que inducen en el lector las ilusiones de objetividad, verosimilitud y familiaridad (Martínez Bonati 2004: 34-36). La fidelidad a la vida de las ficciones realistas se expresa también en la emergencia de las diversas posiciones de deseo que se actualizan y entran en conflicto en el entramado social. Como sugiere Girard, "el novelista no es un realista del objeto sino un realista del deseo" (1963: 59). Los héroes de las novelas realistas desean, pues, sobre la base de un "tercero [que] está siempre presente en el nacimiento del deseo" (1963: 20): un modelo (mediador) al que los personajes novelescos procuran aproximarse mediante la imitación. La distancia que se establece entre el mediador y el sujeto define lo que Girard llama mediación externa y mediación interna ${ }^{6}$. La mediación externa se

\footnotetext{
La novela, que hoy sólo conserva la primera parte del título, se publicó como folletín en el diario La voz de Chile, en 1862.

5 Ficciones fundacionales. Las novelas nacionales en América Latina de Doris Sommer (utilizamos la edición del Fondo de Cultura Económica de 2004) es el único estudio de los examinados que considera las proposiciones teóricas de René Girard. Nuestra lectura amplifica, desde esta perspectiva, los análisis realizados por Sommer.

6 René Girard señala: "Hablaremos de mediación externa cuando la distancia es suficiente como para que las
} 
encuentra presente en las novelas realistas del siglo XIX; sin embargo, es la mediación interna, en la que un personaje imita a su modelo disimuladamente hasta el punto de convertir su fascinación en repudio, la que se apodera de la dimensión del deseo permeando toda la estructura novelesca. Las consecuencias de la mediación interna se elucidan en un sentimiento conflictivo que rige recíprocamente la relación del sujeto y el modelo: la fascinación por el modelo en la medida en que éste se convierte en un obstáculo transmuta en envidia, rivalidad y odio. Derivan de este desplazamiento las conexiones entre deseo mimético, violencia y mal propuestas por Girard. Los estudios sobre el deseo mimético en las escrituras de Cervantes, Flaubert, Stendhal, Proust y Dostoievski realizados por Girard (1984) deben completarse, sin embargo, con estudios de los novelistas fundamentales del realismo español (Pérez Galdós y Leopoldo Alas) y de los novelistas latinoamericanos del siglo XIX, entre los que Alberto Blest Gana ocupa un lugar de privilegio. Asumimos este desafío y ponemos los resultados en relación con la intención utópica de la novela, problema que, según Faletto y Kirkwood (1976), merece especial atención en la escritura literaria de Blest Gana ${ }^{7}$.

Releer hoy día la novela de Blest Gana no implica sólo revisar críticamente las estéticas romántica y realista, a la vez que sus vinculaciones con el complejo Chile de mediados del siglo XIX. Implica también la posibilidad de producir una mirada de nuestro presente y descubrir las potencias de futuro que residen todavía en esos libros del pasado que son verdaderos guardianes del sueño de una patria que (aún) no existe.

\section{Violencia mimética}

No son sólo los personajes de medio pelo quienes tratan "en forma patética e infructuosa de acceder a la clase alta, imitándola en sus modas y gustos” (Hosiasson 2009: 268). Los personajes que integran la burguesía santiaguina también se encuentran regidos por el deseo mimético que convierte, según Girard (1963), a los hombres en modelos a imitar. Dámaso Encina, Simón Arenal, Fidel Elías, Emilio Mendoza, Francisca Encina, por ejemplo, son personajes en los que es posible advertir "la falsificación burda" (Faletto y Kirkwood 1976: 192) de sus mediadores.

Dámaso Encina es el "tipo del hombre parásito en la política, que vive siempre al arrimo de la autoridad y no profesa más credo político que su conveniencia particular y una ciega adhesión a la gran palabra Orden realizada en sus más restrictivas

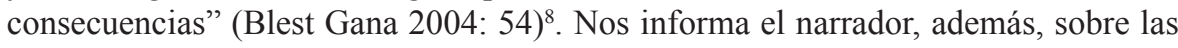
estrategias empleadas por el personaje para escalar económica y socialmente, entre las que sobresalen la turbia historia con José Rivas, el matrimonio con Engracia Núñez, quien "poseía una herencia de treinta mil pesos, que inflamó la pasión del joven Encina hasta el punto de hacerle solicitar su mano" (13), y el recurso de "la usura en

\footnotetext{
dos esferas de posibles, de las cuales el mediador y el sujeto ocupan los centros, no puedan entrar en contacto. Hablaremos de mediación interna cuando esa misma distancia es lo bastante reducida como para que las dos esferas se penetren más o menos profundamente” (1963: 13).

Faletto y Kirkwood escriben: "No sólo es destacable la función crítica que desempeña el liberalismo romántico respecto a los valores que informan la sociedad burguesa, sino que también adquiere particular relieve su intento de construir valores alternativos; ambos, crítica e intención utópica, dejarán a la vista el carácter derruido de la ideología burguesa" (1976: 142).

8 Todas las citas de Martín Rivas, de ahora en adelante, irán acompañadas sólo con el número de página. Véanse obras citadas.
} 
grande escala, tan común entre los capitalistas chilenos” (14). Dámaso Encina, como prácticamente todos los personajes de la novela, rinde culto al dinero, considerado el valor social por excelencia ${ }^{9}$. Desde esta perspectiva deben comprenderse los proyectos matrimoniales de Clemente Valencia, quien "quería aumentar su caudal con la herencia probable de Leonor" (20), y de don Fidel Elías, quien le indica a su mujer: "Agustín es un buen partido que no debemos dejar escaparse y yo hablaré con Dámaso sobre este negocio, puesto que yo debo hacerlo todo en esta casa" $(101)^{10}$.

Dámaso Encina es un fiel representante, si seguimos los planteamientos de Gabriel Salazar (2006), de la élite mercantil que surge en la época colonial, tiene una significativa participación en el período independentista y se consolida en la etapa republicana. Los esfuerzos de dicha élite se encaminaron a preservar y amplificar su poder económico, además de ejercer el control político de la nación. El desprecio que el narrador (y el autor) manifiesta por el "mercader" santiaguino, desde este acceso, se relaciona con una crítica a la República autoritaria y mercantil que se arraiga en Chile, si volvemos a las proposiciones de Salazar, con el modelo portaliano. El culto al dinero, sin embargo, es sólo uno de los rasgos de este representante de la élite mercantilista. Merece especial atención el análisis del rol de lector de periódicos del personaje, evidenciado en los siguientes fragmentos:

Don Dámaso, que tenía perdida la esperanza de ser comisionado por el Gobierno, como se le había hecho esperar, se hallaba en aquella noche bajo la influencia de los periódicos liberales, cuyos artículos recordaba perfectamente (54).

Este fluctuaba entre el ministerio y la oposición a merced de los consejos de los amigos y de los editoriales de la prensa de ambos partidos (20).

La lectura de periódicos liberales y conservadores afecta la opinión política de don Dámaso. El personaje fluctúa por ello entre la adhesión y la oposición al gobierno. Blest Gana, por un lado, pareciera criticar mediante la creación de este personaje las alianzas de liberales y conservadores que se desarrollan en 1857, fecha señalada por Jaime Concha como "el horizonte insuperable de su ideología liberal" (1977: XXII). Revela, asimismo, el desencanto del escritor ante la aparente imposibilidad de la instalación social de su moderado ideario liberal. Blest Gana, por otro lado, hace visible la capacidad del lenguaje de convertirse en mediador del deseo de los individuos, inscribiéndose así en una tradición literaria que, en lengua castellana, se inicia con El ingenioso hidalgo don Quijote de la Mancha, novela en la que Alonso Quijano imita un modelo (Amadís de Gaula) descubierto en sus lecturas de novelas

$9 \quad$ Ricardo Latchman: "Blest Gana va a presentar, a menudo, conflictos en que el dinero actúa como fuerza social y se vincula a las posibles alianzas matrimoniales en un medio donde se le concede una importancia categórica a las suculentas dotes o a las oportunas herencias” (1959: 13). El importante trabajo de Faletto y Kirkwood desarrolla de un modo más riguroso la significación novelesca del culto al dinero. Uno de los aportes de los autores establece que "la posibilidad de quebrar y sobreponerse a la barrera del dinero, es concebida como el triunfo del romanticismo" (1976: 145) desplegado en la escritura de Blest Gana.

10 Guillermo Araya señala, como la mayoría de los críticos, que existen dos temas principales que recorren toda la obra de Blest Gana: el amor y el dinero. Destaca que "el tema amoroso tiene tres desarrollos: conduce al matrimonio (héroes logrados), a la fuga (fracaso y normalmente muerte) o, por último, se presenta bajo la forma de amor extramatrimonial, de unión libre entre amantes (también en este caso deriva a la muerte o al fracaso) [...] Hay un cuarto desarrollo posible para el tema amoroso. Sólo se presenta dos veces. Y en los dos casos son personajes femeninos los que aportan tal desenvolvimiento. Es el amor abnegado. El sacrificio de una mujer enamorada para que su amado condiga a otra mujer" (1987: 172). 
de caballería. Los deseos del lector "de los editoriales de la prensa de ambos partidos" surgen, pues, sobre la base de la imitación de las ideas políticas que se actualizan en el espacio novelesco.

Francisca Encina es otro personaje regido por el deseo mimético. Sabemos que ella defiende ideas muy provocadoras para la época: cree en la democracia, en la participación de la mujer en política y en conferir importancia civil al pueblo. No es difícil que los lectores quedemos atrapados en la trampa del deseo mimético y lleguemos a considerar a doña Francisca una mujer pasional y auténtica, representante de una “estrecha relación entre cultura y progresismo político" (Faletto y Kirkwood 1976: 169); no obstante, advertimos la verdadera naturaleza de sus deseos sólo cuando el narrador nos informa que ella "había leído algunos libros y pretendía pensar por sí sola” (31). Doña Francisca, en efecto, ha leído al poeta romántico Espronceda y, fervientemente, a George Sand, modelo al que imita para opinar en sociedad e intentar huir del tedio que impera en su relación conyugal. Ella se vincula en muchos aspectos a Emilio Mendoza, el plagiador de Campoamor, pues se encuentra cautiva de lo que Girard denomina la mediación externa. Sus deseos según el otro buscan llenar inútilmente el vacío ontológico que se ha intensificado con un matrimonio en donde los sueños románticos no cristalizarán jamás. El gran otro ante el cual no pueden resistirse los personajes dominados por la mediación externa, desde este acceso, es el lenguaje literario. Lo extraordinario es que el mismo lenguaje literario es capaz de poner en evidencia la mentira que reside en el giro del lenguaje.

Agustín Encina, quien "usaba gran profusión de galicismos y palabras sueltas de aquel idioma para hacer creer que lo conocía perfectamente” (18), imita modelos franceses. Se convierte así en otro esclavo de los deseos mediatizados y en un verdadero espejo en el que se reflejan las indigencias de una parte importante de la sociedad chilena ${ }^{11}$. La identidad de Agustín se define por la incapacidad, llevada hasta la caricatura, de desear sin la mediación del otro y, por consiguiente, de huir de la prisión del deseo mimético. Agustín deviene en un snob, es decir en "un imitador [que] copia servilmente a las personas a quienes envidia el nacimiento, la fortuna o lo chic... El snob no se atreve a confiar en su criterio personal y no desea sino los objetos deseados por otros. Es por lo que es esclavo de la moda" (Girard 1963: 22) ${ }^{12}$. Dos fragmentos ejemplifican notoriamente la condición de snob, adorador de lo chic y esclavo de la moda, del "siútico" que no sólo imita a sus modelos franceses, sino que incluso a los bailarines de los picholeos en casa de doña Bernarda:

11 Un texto de Vicente Pérez Rosales, quien se refiere críticamente a los efectos contagiosos de la imitación de modelos franceses en la sociedad chilena de mediados del siglo XIX, es clave en este sentido: "Entonces todo recién llegado del mágico París, a más del necio orgullo que ostentan los que ahora llegan, contábamos con los atractivos que da la moda al corte de un vestido, con la grata sorpresa de aquél que oye hablar en francés a un 'pehuenche' y con un caudal de portentosas descripciones, de chistosos galicismos, de muy variados y siempre elegantes nudos de corbatas y de no pocos nuevos pasos que agregar al baile de las cuadrillas. Teníamos, en fin, para muchas mamás y no pocos bobos todos los encantos de los trajes de moda recién desencajonados" (Cit. en Alone 1940: 45).

12 Amador Molina, sin duda, es un imitador del mismo tipo que Agustín Encina. La distancia y simpatía que el lector puede establecer con uno y otro pareciera depender de las atenuaciones cómicas introducidas por el narrador. Amador, asimismo, imita a los acaudalados señores, específicamente a Dámaso Encina y Fidel Elías, de quienes copia su (secreta) capacidad de metamorfosearse en liberal o conservador, según sus intereses lo requieran: "En tiempo de elecciones es un activo patriota si la oposición le paga mejor que el Gobierno, y conservador neto si éste gratifica su actividad; a veces lleva su filosofía hasta servir a los dos partidos a un tiempo, porque, como él dice, todos son compatriotas" (60). 
Su pelo rizado, la gracia de su persona y su perfecta elegancia, hacían olvidar lo vacío de su cabeza y los treinta mil pesos invertidos en hacer pasear la persona del joven Agustín por los enlosados de las principales ciudades europeas (15).

Repitiendo todos estas últimas palabras, hasta que el elegante creyó que las voces que oía las arrancaba el entusiasmo, cayó de rodillas a los pies de su compañera, para imitar a los que le habían precedido (69).

Prisionero de la mediación interna, donde se encuentra la verdad profunda de las sociedades modernas, y de la mediación externa, el primogénito de los Encina necesita ocupar el lugar señalado por sus modelos. El amor pasión por Adelaida, como sabemos, es una ilusión, ya que él sólo desea imitar a los hombres de París, quienes acostumbran tener amores clandestinos, y a los amantes de la literatura romántica.

- Pues hombre, es la verdad, no hay ninguna niña de nuestros salones que me guste tanto como Adelaida.

-Malo, dijo Rivas.

- ¿Por qué?

- Porque ese amor puede convertirse en pasión y hacerle cometer alguna locura.

- ¿Qué llama usted locura? En París todos tienen esta clase de amores.

- Llamo locura, por ejemplo, que usted llegase a querer casarse con ella.

- ¡Bah, querido; usted no conoce el mundo! Todas estas chicas saben que un joven como yo no se casa con ellas (106).

El corazón del hijo de don Dámaso palpitó de alegría al ver abrirse el postigo que daba la señal de que era esperado. Considerábase en ese instante como el héroe feliz de alguna novela, y de antemano se regocijaba su orgullo al pensar que una mujer bonita le amaba lo bastante para sacrificarle su honra (136).

Una posición de deseo como la de Agustín desencadena irremediablemente otras posiciones de deseo similares. El deseo, en efecto, es contagioso. ¿No son acaso los deseos de Amador, de doña Bernarda y de la propia Adelaida exacerbados por el deseo mimético de Agustín? Amador, en efecto, ve una posibilidad para aproximarse aún más a la clase que envidia y aborrece. Bernarda Molina, cegada por la ilusión creada por sus hijos, ve una oportunidad de ascenso social, que ya ha buscado mediante el proyecto de matrimonio de Edelmira y Ricardo Castaños, y de materializar la mentira de otro imitador, don Damián, su marido, quien "pretendía ser de buena familia" (60). Adelaida Molina, por último, "cultiva en su pecho una ambición digna de una aventurera de drama: quiere casarse con un caballero. Para las gentes de medio pelo, que no conocen nuestros salones, un caballero o como ellas dicen, un hijo de familia, es el tipo de la perfección, porque juzgan al monje por el hábito" (60).

Blest Gana censura los amores clandestinos de Agustín con Adelaida, en la medida en que desembocan en una situación inminentemente escandalosa. El escándalo que atemoriza a Agustín y su familia, que es evitado por Martín Rivas, quien tiene clara “conciencia de la falsedad” (Faletto y Kirkwood 1976: 197) de las relaciones entre sujetos heterogéneos, expresa la sanción al deseo perturbador del orden establecido, revelando el respeto a la ley de homogamia y, por consiguiente, las dificultades de movilidad social de la sociedad chilena del siglo XIX ${ }^{13}$. Lo mismo podemos

Sobre este interesante problema, recomendamos el artículo de Óscar Mac-Clure "Clases medias chilenas y transgresión de la homogamia: una perspectiva histórica". Véanse obras citadas. 
decir de los amores clandestinos de Rafael San Luis y Adelaida, donde cristaliza la inconcebible cruza entre sujetos de sectores sociales diferentes. Más grande es el castigo que deben sufrir estos personajes, porque es mayor el desorden que generan en el entramado social novelesco. La mezcla de dos grupos heterogéneos cifrada en un hijo ilegítimo resulta, desde la perspectiva de la verdad del autor, en extremo peligrosa; tal vez por ello el mismo San Luis, desencantado del mito romántico del seductor, descubre la magnitud de su crimen moral: "La vida impura de un seductor sin conciencia me hizo avergonzarme ante la mía, y los placeres ilícitos en que me había lanzado, lejos de curarme de mi mal, me dieron la conciencia de mi bajeza, haciéndome considerar indigno del amor de Matilde” (82).

Hay otras intrigas amorosas que no tienen un desenlace similar a los previamente mencionados. Nos referimos a los casos de Rafael San Luis y Matilde Elías y de Martín Rivas y Edelmira Molina. Las posiciones de deseo de los mundos imaginarios del romanticismo literario ${ }^{14}$, repudiadas por Blest $\mathrm{Gana}^{15}$, intervienen de manera evidente en el desarrollo y desenlace de los acontecimientos. La lectura de textos literarios es lo que predispone a Rafael San Luis y a Edelmira Molina al deseo de un amor pasión idéntico al de las lecturas de su fascinación. Recordemos que el amor de Rafael San Luis por Matilde nace en un contexto dominado por inclinaciones literarias románticas: "a los dieciocho años me gustaba la poesía, y rimé con ese calor en el pecho de que habla Descartes cuando describe el amor. A esa edad conocí a la dueña de ese retrato" (77). La novela revela una clave que nos permite comprender una de las razones del fracaso del amor: la génesis de la ilusión amorosa se encuentra en la interacción del lector (San Luis) y la mentira romántica. El distanciamiento de la verdadera pasión amorosa se debe a que en el origen del amor se inscribe la imitación de modelos literarios. El amor romántico por Matilde, los placeres ilícitos junto a Adelaida y el devenir revolucionario de Rafael San Luis lo convierten en un personaje extraño y anárquico, extraordinariamente peligroso para el orden social soñado por Blest Gana. No impide esto que el narrador, Martín Rivas y el mismo autor, portadores del poder de iluminar y corregir las desviaciones del deseo, se sientan seducidos por San Luis: "Había, en verdad, cierto aire de misterio en torno de aquel joven, cuya poética belleza llamaba la atención a primera vista. Martín observó con curiosidad sus maneras, en las que resaltaba la dignidad en medio de la sencillez, y la vaga melancolía de su voz le inspiró al instante una poderosa simpatía” (43) ${ }^{16}$. El idealista Rafael San Luis, en suma, constituye lo heterogéneo romántico en la novela de Blest Gana, razón por la que es sometido a rituales de expulsión: el escándalo social, la pérdida del (aparente) amor de Matilde y la muerte

14 Blest Gana escribe: "La poesía chilena ha sido hasta hoi esencialmente sentimental: ha buscado su principal inspiración en los dolores del alma que, si es cierto que abundan en la tierra, no constituyen el estado normal del hombre; ha vertido demasiadas lágrimas para que la espresion de una melancolía perenne pueda conmover; ha tocado con demasiada frecuencia las fibras del corazon para que haya podido conservar la esquisita sensibilidad de sus sentimientos. Siendo, pues el plañidero acento que resuena en las obras de Byron i en las de sus numerosos émulos, lo que forma el rasgo mas característico de nuestra poesía, fácil es concebir su falta de originalidad i el poco interes que despierta en los que quisieran verla remontar su vuelo a mas elevadas regiones” (1861: 87).

15 Véanse su discurso "Literatura chilena. Algunas consideraciones sobre ella" (1861).

16 Entre los ámbitos del poder y del placer se produce una interesante red de intercambios y contagios, por ello es que advertimos una extraña fascinación del narrador, de Rivas, de Blest Gana por los deseos perturbadores que señalan y expulsan del espacio novelesco. 
en medio de la confusión revolucionaria. Sus sueños y amarguras lo convierten, junto a Edelmira Molina, en un personaje fundamental, ya que experimenta la desilusión y el reencantamiento románticos. Dos son, en este sentido, las posiciones románticas que mueven al personaje: la ilusión y desilusión del amor romántico, $\mathrm{y}$, resultado de esta desilusión, el despliegue del deseo revolucionario, que surge como posibilidad de olvido del deseo amoroso. Rafael San Luis, cautivo del modelo mimético, no puede dejar de "recaer constantemente en el infierno del deseo" (Girard 2010: 197). Sus posiciones de deseo enseñan el influjo de la mímesis romántica (amor y revolución). La muerte del héroe expresa, además de la afirmación romántica de "la propia vida y negación de la vida impuesta” (Faletto y Kirkwood 1976: 150), la expulsión definitiva de la imitación romántica y del desorden asociado al despliegue de los placeres prohibidos.

Edelmira Molina es una "niña suave y romántica como una heroína de algunas novelas de las que ha leído en folletines de periódicos que le presta un tendero aficionado a las letras" (60). Procura como Alonso Quijano (El Quijote), Ana Ozores (La Regenta), Juan Santiuste (Aita Tettauen) y Emma Bovary (Madame Bovary) transformar su realidad a partir de la cristalización de los sueños románticos. Anhela por ello la compañía de un hombre que se encuentre en "armonía con los héroes de folletín" (61). Ese hombre, como sabemos, es Martín Rivas, personaje sin historia (recién ha llegado a Santiago) que puede ser imaginado según las expectativas de Edelmira: "había encontrado en Martín el tipo de héroe que las mujeres aficionadas a la lectura de novelas se forjan en la juventud" (112), a quien sólo podía ver "rodeado de la aureola con que la imaginación de las niñas sentimentales engalana la frente de los cumplidos héroes de novela. Y hemos dicho ya que Edelmira, a pesar de su oscura condición, leía con avidez los folletines de los periódicos que un amigo de la familia le prestaba" (145). La proximidad que mantienen Martín Rivas y Leonor Encina, por otro lado, además de revelar las rivalidades miméticas entre Leonor y Edelmira, intensifica en la última el deseo por el joven provinciano (lo mismo ocurre en el caso de Leonor, cuando advierte la amistad de Martín y Edelmira, así como la belleza de ésta ${ }^{17}$ : "El joven cobraba entonces a sus ojos las proporciones gigantescas del hombre amado por otra mujer: el adagio sobre la fruta del cercado ajeno está realizándose todos los días, aun en los amores más ideales y platónicos (213). Será la lectura de una carta de Martín, como debe recordar el lector, lo que termina de encender la pasión amorosa en Edelmira ${ }^{18}$. Tres situaciones, por lo menos, se conjugan en este momento: a) la inclinación romántica de Edelmira, b) la carta es el espacio discursivo más propicio a mediados del siglo XIX para expresar los afectos amorosos que se encuentran fuera del matrimonio y c) los lugares vacíos que deja la escritura de Rivas son

Guillermo Araya ha estudiado la estética del triángulo en la novelística de Alberto Blest Gana. No profundiza en la importancia de los deseos triangulares y las rivalidades miméticas, pero llega a valiosas conclusiones: "La existencia de triángulos eróticos trae por consecuencia inevitable el surgimiento de rivalidades" (1987: 178).

18 En la novela se lee: "Edelmira recibió esta carta en la tarde de manos de la criada de su casa, de quien había tenido que valerse para entablar su correspondencia con Martín. Las teorías que en pocas palabras desenvolvía el joven sobre el amor encendieron el alma de Edelmira, haciendo en ella brillar el fuego de una verdadera pasión. Pensó que el corazón de aquel hombre era un tesoro y lo deseó con avidez. Las formas sentimentales de un capricho romántico cobraron en su meditación las proporciones exageradas de un bien que era preciso adquirir a toda costa; con tal convicción, la hipótesis de que las palabras de amistad encubrían la delicada expresión de un amor que buscaba una esperanza, llegó, poco a poco, a convertirse en su espíritu casi en certidumbre" (260). 
llenados sobre la base del horizonte de expectativas de Edelmira, que surge a partir de sus lecturas románticas ${ }^{19}$.

La insistencia del narrador por recordarnos que Edelmira "era dada a la lectura de novelas y por naturaleza romántica" (157) debe relacionarse con la presentación que hace Rafael San Luis de la joven: "Es una pobre muchacha desgraciada, porque se avergüenza de los suyos y aspira a gentes que la valgan, a lo menos por el lado del corazón" (75). Rafael San Luis, influenciado por el desencanto del amor romántico, parece saber algo que desconoce la joven lectora de folletines románticos: los proyectos amorosos cubiertos por el velo de la mentira romántica están condenados al fracaso, cuando entran en colisión con la prosaica realidad. Así le ha ocurrido a él y así le ocurrirá a Edelmira, quien es condenada a la infelicidad junto a Castaños.

Blest Gana, como bien lo ha advertido Juan Poblete, instala la lectura "en el centro estructurante de Martín Rivas" (2003: 83). La mayoría de los personajes experimentan los efectos negativos que surgen de la imitación de modelos literarios, por lo que son sometidos a rituales de expulsión. Esta es una verdadera estrategia conducente a destruir simbólicamente las formas literarias que dificultan la instalación de la novela nacional y, por consiguiente, el encauzamiento disciplinario de la sociedad chilena. La borradura de las formas literarias preexistentes debe considerarse en conexión con el afán de legitimar el proyecto literario-pedagógico de Blest Gana.

Los deseos de los personajes de Martín Rivas se articulan sobre la base de la mediación externa y la mediación interna. Girard escribe sobre esta segunda forma de mediación: "En el caso de los novelistas que escriben sobre la mediación interna, lo que triunfa es la envidia y los celos morbosos. Stendhal habla de 'vanidad', Flaubert y sus críticos hablan de bovarismo; Proust revela las operaciones del esnobismo y de L'amour-jalousie" (1984: 22). Privilegiamos, en este artículo, la noción de vanidad de Stendhal, quien "designa con [ese nombre] todas estas formas de 'copia', de 'imitación'. El vanidoso no puede extraer sus deseos de su fuero interno; los toma prestados de otros. [...] Para que un vanidoso desee un objeto basta el convencerlo de que ese objeto es deseado ya por un tercero al que se le asigna cierto prestigio" (1963: 9-10). Los hombres y mujeres de la alta burguesía y del medio pelo, capa social a la que Guillermo Araya denomina bastarda, pues "huye del pueblo pero nunca accede a la clase superior" (1987: 175), están gobernados por la vanidad. Santiago de Chile en pleno siglo XIX es una sociedad de imitadores. Eso nos reitera morosamente Martín Rivas, novela que revela, en este sentido, una "visión profunda en las almas de los personajes llevados a la escena" (Silva Castro 1941: 579). Una sociedad regida por la vanidad, por el deseo según el deseo del otro, deshace la doxa romántica sobre la autonomía del sujeto y la espontaneidad y naturalidad del deseo; al mismo tiempo, permite explicar el origen del mal retratado en las novelas realistas. La desilusión del héroe, ejemplificada con Rafael San Luis y Edelmira Molina, no sólo permite apreciar la falacia del deseo mimético, sino también ilumina críticamente la sociedad representada en la novela. Martín Rivas, en la medida en que se constituye en un dispositivo imaginario que cifra un verdadero archivo de la vida de hombres y mujeres atrapados por deseos imitados, ilumina las ideologías, el aparato normativo y las relaciones de poder y de saber que dominan en la sociedad chilena del siglo XIX.

19 "La pareja: comportamientos, afectos, sentimientos y pasiones" (2005) de René Salinas es un interesante estudio sobre la significación de la carta en el contexto de las pasiones del siglo XIX. 
Una de las razones fundamentales de la corrupción moral de la sociedad santiaguina, cifrada en el culto al dinero, es la hegemonía del deseo mimético, que produce "individuos que se creen libres y se aferran con furia a sus falsas diferencias" (Girard 2010: 53). En la novela leemos:

La guerra que un amante odiado declara contra su preferido rival en el corazón de una mujer, sirve las más veces para aumentar su prestigio, por esa tendencia hacia la contrariedad, natural a la índole femenil. Por esto, mientras mayor empeño desplegaba el oficial para dañar a Martín en el ánimo de Edelmira, con mayor fuerza se desarrollaban en ésta los sentimientos opuestos en favor de aquel joven melancólico, de delicado lenguaje, que daba al amor la vaporosa forma que encanta el espíritu de la mujer (145).

$\mathrm{Al}$ estiramiento con que al principio se habían mostrado para copiar los usos de la sociedad de gran tono, sucedía esa mezcla de confianza y alambicada urbanidad que da un colorido peculiar a esta clase de reuniones. Colocada la gente que llamamos de medio pelo, entre la democracia que desprecia, y las buenas familias, a las que ordinariamente envidia y quiere copiar sus costumbres, presentan una amalgama curiosa, en las que se ven adulteradas con la presunción las costumbres populares y hasta cierto punto en caricatura las de la primera jerarquía social, que oculta sus ridiculeces bajo el oropel de la riqueza y de las buenas maneras (67).

Odio, enemistad, envidia, desorden, imposibilidad de encuentro con el otro, egoísmo del yo: signos distintivos de una sociedad dominada por los deseos miméticos. Así lo demuestran los fragmentos previamente citados, donde resalta la violencia individual (que Castaños dirige hacia Rivas) y colectiva (recíproca entre el "medio pelo" y las "buenas familias"). Las diferencias, específicamente en la última relación, se arraigan en la rivalidad mimética y terminan anulándose en la violencia recíproca que gobierna dicha relación ${ }^{20}$. Martín Rivas textualiza las operaciones subterráneas del deseo en el país que le correspondió vivir a su autor. Enseña algo que resulta impensable en las escrituras dominadas por el mito romántico de la autonomía del sujeto, esto es, que el deseo mimético, aquél que satisface momentáneamente la sed de trascendencia y de infinito, siempre cristaliza a partir de la presencia de un modelo a imitar que puede surgir de la literatura (mediación externa) o de las relaciones sociales (mediación interna). La verdad de la novela -que es también la verdad del autor- no es, con todo, la verdad del deseo mimético, generador de "envidia”, “desprecio” y "ridiculeces". La verdad de la novela se relaciona con la liberación del deseo mimético que contagia e inunda de violencia las relaciones individuales (Amador y Agustín, Castaños y Rivas, entre otros pares miméticos) y colectivas (Chile y Francia, burguesía mercantil y medio pelo), y, por lo mismo, con el sueño de otras posiciones de deseo que posibiliten una relación distinta con el otro. Esta verdad profunda reside en el centro mismo del proyecto estético y político impulsado por el movimiento intelectual de 1842. Sus integrantes y los escritores de la generación inmediatamente posterior tienen conciencia del contagio mimético y sus interferencias. Lastarria y Blest Gana, por ejemplo, dialogan elocuentemente en lo que se refiere a la lectura y valoración negativa de las relaciones miméticas que impiden el despliegue de una literatura original, nacional y civilizadora. La imitación, sostiene Lastarria, es el recurso

Véanse Girard, René. 1982. El misterio de nuestro mundo. Claves para una interpretación antropológica. Diálogos con J. M. Oughourlian y G. Lefort. Salamanca: Ediciones Sígueme. 337-338. 
mas peligroso para un pueblo, cuando es ciega y arrebata, cuando no se toma con juicio lo que es adaptable a las modificaciones de su nacionalidad. Tal vez ésta es una de las causas capitales de las calamitosas disidencias que han detenido nuestra marcha social, derramando torrentes de lágrimas y de sangre en el suelo hermoso y virjinal de la América española (1842: 9).

El inquietante descubrimiento de Lastarria no dice otra cosa: el deseo mimético produce violencia y sufrimiento. Lo mismo dice Martín Rivas, cuya densidad significativa pareciera encontrarse en las posiciones de deseo mimético que penetran toda la estructura novelesca.

\section{Pensamiento utópico}

Blest Gana se propone instalar las bases de la literatura chilena a partir de procedimientos realistas que le permiten copiar y evaluar las particularidades de las diversas esferas sociales y sus relaciones de fuerza. Iluminar y hacer visible los vicios y errores sociales son algunos de los objetivos de la ficción realista, que debe vincularse, en el caso de Blest Gana, con un proyecto de nación en el que la literatura (la novela nacional) cumple una función didáctica-moralizante coincidente con la "tarea civilizadora" asumida por los escritores e intelectuales liberales del siglo XIX ${ }^{21}$.

El héroe de la novela de Blest Gana pareciera triunfar, como lo ha propuesto Ricardo Latchman, "por su carácter, por su honestidad y sus virtudes. Más que un arribista típico, como los de Balzac, es el precursor de una dinastía de escaladores de situaciones sociales y económicas” (1959: 39). Raúl Silva Castro señala que es la "superioridad del talento y de la virtud" (1941: 402) lo que lo convierte en un verdadero "místico de la voluntad" (1941: 585) ${ }^{22}$ y posibilita el ascenso social mediante la conquista del amor de Leonor Encina; por tal motivo, y distanciándose de las tesis de Domingo Melfi (1938), Alone (1940) y Luis Merino Reyes (1959), Silva Castro concluye que la novela no textualizaría los problemas inherentes "al nacimiento de una 'nueva clase', a la cual le correspondería el privilegio de gobernar una vez que, por cansancio propio o por cualquier otro motivo, dejara de hacerlo la aristocracia tradicional simbolizada en Dámaso Encina" (1941: 400). Jaime Concha plantea que Rivas es "un claro y simple representante de la burguesía, pero no en el nivel de su consolidación económica, sino en el de la instauración ideológica (Concha 1977: XXIV) ${ }^{23}$. Faletto y Kirkwood (1976), por otro lado, proponen que el

21 Recuérdese que Lastarria, en su conocido discurso de 1842, aboga por una literatura crítica, distanciada de la herencia colonial, capaz de ilustrar al pueblo y consolidar el espíritu nacional. Ricardo A. Latcham, en "Las ideas del movimiento literario de 1842", escribe: "Sarmiento, en 1841, precedía con intuiciones certeras a los atisbos nacionalistas del discurso de Lastarria en la Sociedad Literaria de Santiago, el 3 de mayo de 1842” (1942: 160).

22 Raúl Silva Castro escribe: "Blest Gana es por antonomasia el novelista de la voluntad chilena, es decir, de aquella forma de voluntad que más frecuentemente muestra el hombre nacido en este suelo y procedente de las razas que lo pueblan. Cierto querer tesonero y templado, que tendrá en la juventud todos los arrebatos pero que más tarde se temperará bajo el velo de un deseo de adaptación que no es cobardía sino prudencia; cierta industriosa tenacidad que lleva al hombre a buscar otro camino cuando ha visto que el antes hallado no le conduce al fin que se ha propuesto: tales son los principales rasgos de esta voluntad que hallamos en los personajes de Blest Gana" (1941: 589). Asimismo, Faletto y Kirkwood (1976) han destacado, a partir de la singularización del héroe romántico, el valor de la juventud en la construcción de los héroes novelescos de Blest Gana.

23 Resulta interesante relacionar la tesis de Concha con el proyecto de Dámaso Encina, representante de la burguesía mercantil. Sabemos que este personaje desea convertirse en senador de la República. Si examinamos uno de los 
éxito amoroso, social y económico del héroe, además de establecer la crítica al orden burgués, expresa el triunfo de la individualidad (de la aristocracia del pensamiento y del sentimiento) exaltada por el liberalismo romántico del autor.

Blest Gana, dominado por la crisis moral de su época y la inminencia del fracaso de sus ideas ilustradas y liberales, construye un personaje que encierra una aspiración refractaria a los valores burgueses que predominan en la sociedad conservadora y capitalista de Santiago de Chile. No es un personaje, por consiguiente, copiado de la realidad social, sino más bien un personaje que surge desde el ámbito de la imaginación utópica de su autor. Su emergencia en el espacio novelesco posibilita observar y examinar, a veces satíricamente, la realidad, así como "visualizar posibilidades"24 o "nuevas perspectivas posibles"25. Martín Rivas produce así lo que Ernst Bloch denomina ventanas utópicas: "toda obra de arte, toda filosofía central, ha poseído y posee siempre una ventana utópica ante la que se extiende un paisaje a constituir" (Bloch 1959: 728) ${ }^{26}$. Surge, pues, un paisaje a constituir, la visión de una perspectiva posible, en medio de una ciudad dominada por la imitación y el culto al dinero. Comienza a cristalizar en el preciso instante en que Rivas se distancia del deseo mimético y de la vanidad, y explotan las virtudes que lo van a diferenciar de los otros personajes novelescos (su naturaleza enérgica, su voluntad, su estoicismo, el desprecio al dinero, su nobleza espiritual, la positiva valoración del estudio, el respeto por el orden, etc.). Rivas se aleja de lo que podemos considerar la norma inmoral de la realidad ficcionalizada. Deviene por ello en un personaje cuya construcción debe vincularse al equilibrado sueño de su autor: un país no regido, entre otros males, por la imitación de modelos inadecuados.

Las metamorfosis que experimenta Martín Rivas a partir de su relación con el deseo mimético pueden, de alguna manera, visualizarse dentro del marco de los proyectos del héroe: estudiar y regresar de abogado a Copiapó "y cambiar la suerte de los que cifraban en él sus esperanzas" (17), conquistar el amor de Leonor Encina, contribuir a las transformaciones sociales sobre la base de la revolución y asentarse en la tradicional burguesía santiaguina. Recordemos que el narrador nos presenta al joven provinciano seducido por la locuacidad del afrancesado Agustín y por la riqueza de la casa de los Encina: "su inexperiencia le hizo considerar cuanto veía como los atributos de la grandeza y de la superioridad verdaderas, y despertó en su naturaleza entusiasta esa aspiración hacia el lujo, que parece sobre todo el patrimonio de la juventud" (22). La atracción y envidia que provoca en el héroe el espectáculo de la ostentación en la casa de los Encina activa una posición de deseo que debe comprenderse examinando la muy comentada escena de los botines de charol.

posibles significados del concepto ideología, específicamente el de "legitimación de la autoridad" propuesto por Max Weber y discutido por Paul Ricoeur, es factible sugerir que Dámaso Encina busca la legitimación (ideológica) de la autoridad de su grupo, en la medida en que desea apropiarse del espacio político, "lugar privilegiado del pensamiento ideológico” (Ricoeur 1989: 55). Martín Rivas, desde este acceso, no puede reducirse sólo a “un representante de la burguesía” en el nivel "de la instauración ideológica" (Concha 1977: XXIV).

24 Northrop Frye, en "Diversidad de utopías literarias", escribe: "El pensamiento utópico es imaginativo, con sus raíces en la literatura, y la imaginación literaria está menos interesada en alcanzar fines que en visualizar posibilidades" (1982: 62).

25 Paul Ricoeur, en Ideología y utopía, escribe: “[El] desarrollo de nuevas perspectivas posibles define la función más importante de la utopía” (1989: 58).

26 Traducción de Dieter Oelker Link. 
Estas palabras despertaron en su memoria el recuerdo del lustroso calzado de Agustín y sus recientes ideas que le habían hecho salir de la casa. Pensó que con un par de botines de charol haría mejor figura en la elegante familia que le admitía en su seno; era joven y no se arredró con esta consideración ante la escasez de su bolsillo (26).

Rivas desea los botines de charol para aproximarse a su mediador. La vanidad se apodera de esta escena que puede leerse a partir de la emergencia de la mediación interna, entre otras posibilidades, como cifra del deseo de Rivas de ocupar el lugar de su modelo. Debemos considerar, por otro lado, que Rivas se convierte en imitador de un imitador, situación que hace más visible su equivocación. Sabemos que el personaje que se transfigura momentáneamente en una divinidad ante la cual se inclina el héroe es Agustín Encina, personaje evaluado negativamente por el narrador. Blest Gana pareciera escribir esta escena para mostrar los errores que engendra la incorrecta elección del modelo a imitar. No cabe duda que prefigura la conclusión de la novela, en la que Rivas es premiado con el lugar que le correspondía a Agustín. Sin embargo, el aprendizaje y el triunfo del joven provinciano no se deben a la asimilación del modelo mimético, como pareciera sugerirlo Jaime Concha (1977), imperante en el mundo novelesco. Se debe, por el contrario, al aparente distanciamiento del modelo que domina en la realidad social ficcionalizada, lo que permite, por una parte, generar la posibilidad de un contraste que hace más evidentes los vicios y errores sociales, y, por otra, concentrar en un personaje las virtudes que son dignas de imitación y pueden producir, mediante su inserción en la burguesía, "nuevas perspectivas posibles". Coincidimos, sin embargo, con Inke Gunia, quien propone que Martín Rivas

más que propagar una determinada ideología política, intenta retratar -por medio de un narrador heterodiegético y marcadamente autorial- cierto comportamiento social, político y moral general que hay que seguir. La función didáctica de la historia novelesca -usa el término 'estudio social' (214)- ya queda anunciada en la dedicatoria donde se presenta al protagonista como “un tipo digno de imitar” (1994: 120-121).

Leonor, personaje caracterizado por su voluntad de dominio, su inteligencia, su orgullo, sus caprichos y su indiferencia, imagina un hombre que (aún) no existe. $\mathrm{Su}$ deseo no sólo expresa el llamado del amor pasión, sino también la urgente necesidad de una nación que reclama a los hombres y mujeres que la conducirán de un modo distinto al siempre incierto porvenir. Activa, de este modo, la verdadera e indestructible ventana utópica de la novela.

Es verdad; nunca he amado, a lo menos, según la idea que tengo del amor. A veces me ha gustado un joven; pero nunca por mucho tiempo. Ese empeño con que los hombres exigen que se les corresponda me fastidia. Encuentro en ello algo de la superioridad que pretenden tener sobre nosotras, y esta idea hace replegarse mi corazón. Aún no he encontrado al hombre que tenga bastante altivez para despreciar el prestigio del dinero y bastante orgullo para no rendirse ante la belleza (30).

El adverbio de tiempo "aún" llena de futuro el presente de la narración. Constituye una verdadera fisura en el mundo narrado por la cual se desliza una queja y una petición de auxilio a quien está por venir. Ese hombre deseado por Leonor debe despreciar al dios que idolatran los habitantes de Santiago, el dinero, a la vez que 
debe ser lo suficientemente orgulloso para no arredrarse ante la belleza. Agregamos nosotros, el hombre deseado debe estar libre del deseo mimético y de la violencia que lo acompaña. Su signo distintivo es la pasión que, "en Stendhal, es lo contrario de la vanidad... El ser de pasión encuentra en sí mismo, y no en los otros, la fuerza de su deseo” (Girard 1963: 18). Doris Sommer, siguiendo las propuestas de Girard, plantea que las novelas nacionales del siglo XIX “insisten en simplificar el triángulo, en enderezarlo y aplanarlo para formar una pareja que reconoce ser el uno para el otro sin que ninguna mediación sea necesaria y ni siquiera posible [...] La triangulación se produce, pues, de un modo extrañamente fecundo más que frustrante, puesto que los amantes deben imaginar su relación ideal a través de una sociedad alternativa. [La unión de los enamorados] se convierte en el principio mediador que impulsa la narración hacia delante como una promesa” (2004: 35). Los deseos transgresores de Leonor y de Martín nada tienen que ver, por consiguiente, con el deseo vanidoso que encontramos en los personajes del medio pelo y de la burguesía mercantil; de ahí que deban visualizarse dentro del marco de lo que podemos llamar el pensamiento utópico de la novela ${ }^{27}$.

La novela, en lo que respecta a esta intriga amorosa, es un relato progresivo de “lucha entre la voluntad orgullosa y el corazón” (180). La pasión de Leonor se vuelve irresistible sólo cuando es capaz de destruir las murallas del orgullo. Un acontecimiento especialmente significativo es el encuentro con Edelmira, a quien le solicita ayuda para liberar a Martín. Por una parte es la conmovedora escena de humildad y determinación de una mujer que ha agotado todas las posibilidades para ayudar al hombre que ama. Señala, por otra parte, la cristalización de la felicidad estética que, a juicio de Girard, marca el paso de la vanidad a la pasión en las grandes obras literarias. Martín Rivas reúne las características deseadas por Leonor, mujer pasional que se aparta de las normas familiares y sociales que habían generado la "altanería de su carácter", puesto que no se inclina ante los dioses adorados por la sociedad santiaguina ${ }^{28}$. El aprendizaje del héroe, desde esta perspectiva, no puede relacionarse con la homogeneización en los vicios que roen la moralidad del entramado social. Rivas, es cierto, se inserta en la burguesía, pero lo hace apartándose de la vanidad, la ambición, la hipocresía, el

\footnotetext{
Ninguno de los dos personajes, sin embargo, ha estado libre del contagio de los deseos. Recordemos dos episodios en donde la mediación interna es evidente: el episodio de los botines, previamente comentado, y el de los celos que experimenta Leonor al enterarse que una mujer joven y bonita (Edelmira) amaba a Martín.
}

28 Patricia Vilches, en "Martín Rivas, Maquiavelo y la masculinidad decimonónica chilena”, lee la novela como una “óptima propuesta de identidad nacional” (2010: 70). En Martín Rivas el personaje que reúne las características de la masculinidad es sólo el protagonista, quien personifica, por consiguiente, los cuatro aspectos mencionados por Maquiavelo: prudencia, oportunidad, suerte y fortaleza. La pertinencia de su carácter se examina en comparación con otros personajes, como Rafael San Luis, cuya masculinidad está dañada y no posee la fuerza para sobreponerse a sus problemas; Leonor Encina, quien ejerce la masculinidad en su control respecto de sus pretendientes; y Dámaso Encina, quien finalmente cede el sillón de 'príncipe' a Martín, personaje que encarna la movilidad social y en quien se materializa "el ideal político-social de Blest Gana" (2010: 73). Las proposiciones de Patricia Vilches pueden ser discutidas a partir de los planteamientos de Doris Sommer, quien escribe. "En el espacio que abarca una generación, entre 1850 y 1880 aproximadamente, los romances idearon sociedades civiles mediante patrióticos héroes, notablemente afeminados. Como Werther, pero sin dejar que la pasión jamás ofuscara la razón, idealizados jóvenes compartían la apariencia delicada y los sentimientos sublimes de sus también idealizadas compañeras para poder fomentar lazos íntimos. Su heroísmo productivo dependía de ello, sobre todo cuando el machismo matón se convirtió en cosa del pasado en muchos países, por lo menos en aquellos que crearon perdurables novelas de consolidación nacional. Advertiremos, a su debido tiempo, las finísimas manos de Daniel Bello en Amalia, la fragilidad femenina de Rafael San Luis en Martín Rivas, y la facilidad con la que, a la menor provocación, los héroes se desatan en lágrimas en todas las novelas” (2004: 33). 
mercantilismo, el odio y la mentira romántica. Su inserción conlleva la promesa de una transformación social a partir de la destrucción de los dioses que gobiernan en las esferas de la burguesía mercantil y en el medio pelo. La escritura de Blest Gana se encuentra, sin embargo, cautiva de las ideas de la factibilidad de ser burgués de "un modo no burgués" (Faletto y Kirkwood 1976: 151) y de la perfectibilidad de las instituciones. El mito basal sin duda es la formación integral de los ciudadanos sobre la base de una educación liberal, lo que se traduce en la ilusión burguesa del encuentro del juicio y la sensibilidad, de la productividad y la pasión presente, según Doris Sommer (2004), en la unión matrimonial de Leonor (comercio de la capital) y Martín (intereses mineros), verdadera solución simbólica para los problemas de la nación ${ }^{29}$. El pensamiento utópico de Blest Gana, si consideramos sólo a Martín Rivas, pareciera no perturbar el orden social imperante ${ }^{30}$. La posición de deseo de Leonor Encina, desde este acceso, es mucho más transgresora y revolucionaria que la de aquél en quien cree encontrar la promesa de un orden distinto ${ }^{31}$.

La fascinación y repudio del autor por los deseos anárquicos y la sangre que acompañan la revolución es otro rasgo relevante de la novela. Alone y Jaime Concha han destacado los efectos de la Revolución (francesa) del 48 en la personalidad y en la escritura de Alberto Blest Gana. Otros intelectuales y escritores de la época fueron contagiados por la revolución, como ocurre, por ejemplo, con Francisco Bilbao; las consignas revolucionarias producen en Blest Gana un efecto similar al que se da en escritores de la España decimonónica como Benito Pérez Galdós y Leopoldo Alas, quienes experimentan atracción y rechazo por la revolución. Las escenas de la Revolución del 48 “tranquilizan al novelista chileno”, señala Alone (31); su condición de "testigo directo" de la "insurrección de Junio de 1848 y la Comuna de París, en Mayo de 1871" incide en "su obra novelística, tan nutrida, por lo mismo, de historia y de ideales libertarios" (1977: XIV), escribe Concha. Los acontecimientos revolucionarios constituyen, sin embargo, sólo el trasfondo de la novela, como lo sugiere Inke Gunia (1994). Los acontecimientos históricos destacados por los críticos chilenos, así como la adhesión a la estética realista -que incide en la producción de la novela nacional- y al liberalismo romántico, debieron

29 Doris Sommer escribe: "La coherencia nace de su proyecto común [se refiere a las ficciones fundacionales del siglo $\mathrm{XIX]}$ de construir un futuro mediante las reconciliaciones y amalgamas de distintos estratos nacionales imaginados como amantes destinados a desearse mutuamente. Esto produce una forma narrativa consistente que puede asimilar distintas posiciones políticas pues está impulsada por la lógica del amor. Con un final feliz, o sin él, los romances invariablemente revelan el deseo de jóvenes y castos héroes por heroínas igualmente jóvenes y castas: la esperanza de las naciones en las uniones productivas” (2004: 41).

30 Recordemos que Rivas es un verdadero emisario del orden social; por eso contribuye a evitar, así lo hemos sugerido, la unión escandalosa de personajes de mundos heterogéneos (Agustín y Adelaida) y sólo puede considerar a Edelmira como una muy querida amiga.

31 Juan Poblete señala: "La novela nacional, en efecto, intentará ser simultáneamente una obra popular como los folletines, una obra moderna y seductora como las novelas europeas, una obra seria como las que merecen el apoyo del gobierno, una obra original en su apropiación textual de las costumbres nacionales; y, por último, una obra de educación de aquellos que la favorezcan con su lectura (2003: 55). Los planteamientos de Poblete, que surgen del análisis de la relación que se produce entre lectores y escritores en el contexto de la sociedad chilena decimonónica, convierten la lectura de novelas "en una práctica social clave en el proceso de consolidación de la nación (2003: 55). La mujer es fundamental en el sueño de construcción de una nación distinta, en la medida en que, sugiere Poblete, contribuye notablemente a la irrupción y consolidación de la novela nacional, verdadero dispositivo capaz de afectar a lectores subalternos y desplegar una posibilidad de transformación social. Esta situación puede explicar el porqué de la elección de Leonor Encina como portadora de una posición de deseo transgresora y revolucionaria. 
influir, desde nuestra lectura, en el distanciamiento de la utopía revolucionaria y, por consiguiente, en la elección de un personaje de las características de Rivas como héroe novelesco y modelo digno de imitar por los lectores y lectoras del Chile decimonónico. Domina en Martín Rivas, así pareciera sugerirlo el siguiente fragmento, el miedo al desorden que producen las síntesis de heterogéneos y las posiciones de deseo desbordadas de la revolución. Miedo que pareciera no afectar la posición de deseo de Leonor Encina:

Vio entonces el pacífico ciudadano tornarse en foro de acalorados debates su estrado; abrazaron los hermanos diverso bando los unos de los otros; hijos rebeldes desobedecieron la voluntad de los padres, y turbó la saña política la paz de gran número de familias. En 1850 y después en 1851, no hubo tal vez una sola casa en Chile donde no resonara la descompuesta voz de las discusiones políticas, ni una sola persona que no se apasionase por alguno de los bandos que nos dividieron. Licurgo no habría podido aplicar entonces en Chile su ley sobre los indiferentes a la cosa pública, porque no habría hallado delincuentes (53-54).

Dieter Oelker ha estudiado la obra novelesca de Luis Orrego Luco. Su reflexión, que recurre a conceptualizaciones teóricas de René Girard, le permite arribar a conclusiones fundamentales, entre las cuales destacamos la manera cómo la alta sociedad "busca atraer el modelo [que surge de viajes a París y Londres] y confundirse con él, apropiándose de las cosas, decires y hábitos" (1996: 79); la imposibilidad de una acción libre y espontánea, individual o colectiva, en un país gobernado por la imitación, la vanidad y la ansiedad del dinero; la añoranza por un orden social y valórico perdido cuyo sostenedor fue la vieja aristocracia colonial. El heredero de Blest Gana, enfrentado a la degradación moral de su nación, escarba en el pasado intentando encontrar en los ya olvidados valores aristocráticos el país que no existe. Pero su lectura de la realidad social chilena está, como sostiene Oelker, signada por la imposibilidad de superar la violencia mimética que se apodera de todo el entramado social. No hay salida. No hay una posibilidad distinta, sugiere la escritura de Orrego Luco, a la impuesta por los deseos mediatizados y el culto al dinero que intensifican la envidia, la ambición, la enemistad y el odio en todo el entramado social.

El autor de Martín Rivas escribe quizá también para resistir el inminente fracaso de su proyecto de país. Expone críticamente, mediante el despliegue de la pasión y la verdad filosófica novelesca, la violencia mimética y el culto al dinero que rigen incluso hoy día mismo la República de Chile. Revelar el mimetismo y modificar el modelo a imitar (las virtudes inactuales de Leonor Encina y de Martín Rivas son dignas de imitación) abren así la posibilidad de soñar un porvenir distinto. La desilusión, por lo mismo, no paraliza el despliegue del pensamiento utópico. El contrato matrimonial de Leonor y Martín permite visualizar posibilidades inimaginables en la novelística de Orrego Luco. Es Leonor Encina, sin embargo, quien desliza el indestructible deseo revolucionario de un futuro distinto ${ }^{32}$ : "Aún no he encontrado al hombre". Blest Gana renunciará después de Martín Rivas a tematizar en sus novelas el presente degradado de un país mercantil, autoritario y afectado profundamente por la violencia mimética. La renuncia al presente dominado por el mal revela con más intensidad uno de los

32 Iván Carrasco se refiere a este rasgo de la novela de Blest Gana: "Martín Rivas representa una identidad vigente, la burguesía liberal, pero al mismo tiempo anuncia una modificación sustantiva de ella que aún no se ha realizado" (2008: 58). 
sentidos de la literatura de Blest Gana: espacio en donde el sueño de un lugar que (aún) no existe aguarda, fundamentalmente en la figura de Leonor Encina, su fiesta de resurrección.

\section{OBRAS CITADAS}

Alone. 1940. Don Alberto Blest Gana. Biografía y crítica. Santiago de Chile: Editorial Nascimento.

Alegría, Fernando. 1978. “Aspectos fundamentales de la novela romántica latinoamericana”. Mirta Yáñez (compiladora). La novela romántica latinoamericana. La Habana: Casa de las Américas. 61-128.

Araya, Guillermo. 1987. “Alberto Blest Gana”, en Luis Iñigo Madrigal (Coordinador). Historia de la literatura hispanoamericana. Tomo II. Del neoclasicismo al modernismo. Madrid: Cátedra. 163-191.

Balmaceda Toro, Pedro. 1889. Estudios i ensayos. Santiago: Imprenta Cervantes.

Blest Gana, Alberto. 1991. Epistolario Alberto Blest Gana. 1856-1903 (Compilación de Sergio Fernández Larraín). Santiago de Chile: Editorial Universitaria. . 1861. "Literatura chilena. Algunas consideraciones sobre ella. Discurso de don Alberto Blest Gana en su incorporación a la Facultad de Humanidades, leído en la sesión del 3 de enero de 1861". Anales de la Universidad de Chile. 81-93. 2004. Martín Rivas. Santiago: Andrés Bello.

Bloch, Ernst. 1959. Das Prinzip Hoffnung Bd. 2. Frankfurt: Main, Suhrkamp Verlag.

Carrasco, Iván. 2008. "Ambivalencia identitaria en la literatura chilena canónica”. Estudios filológicos 43: 55-62.

Concha, Jaime. 1977. "Prólogo”. Martín Rivas. Por Alberto Blest Gana. Caracas: Biblioteca Ayacucho. IX-XL.

Faletto, Enzo y Kirkwood, Julieta. 1976. Sociedad burguesa y liberalismo romántico en el siglo XIX. Chile: FLACSO.

Frye, Northrop. 1982. "Diversidad de utopías literarias”. Utopías y pensamiento utópico. Frank E. Manuel (ed.). Madrid: Espasa Calpe. 51-81.

Girard, René. 2010. Clausewitz en los extremos. Política, guerra y apocalipsis. Buenos Aires: Katz editores. . 1982. El misterio de nuestro mundo. Claves para una interpretación antropológica. Diálogos con J. M. Oughourlian y G. Lefort. Salamanca: Ediciones Sígueme. . 1984. Literatura, mímesis y antropología. Barcelona: Gedisa.

. 1963. Mentira romántica y verdad novelesca. Caracas: Ediciones de la Biblioteca de la Universidad Central de Venezuela.

Goič, Cedomil. 1991. La novela chilena. Los mitos degradados. Santiago de Chile: Editorial Universitaria.

Gunia, Inka. 1994. "Martín Rivas de Alberto Blest Gana". Apropiaciones de realidad en la novela hispanoamericana de los siglos XIX y XX. Dill, Gründler, Gunia, MeyerMinnemann (eds.). Frankfurt-Madrid: Vervuert. 104-125.

Hosiasson, Laura Janina. 2009. "Blest Gana, Martín y el calavera". Revista chilena de literatura 75: 259-269.

Lastarria, José Victorino. 1842. Discurso de incorporación de D. J. Victorino Lastarria a una Sociedad de Literatura de Santiago, en la sesión del tres de mayo de 1842. Valparaíso: Imprenta de M. Rivadeneyra.

Latcham, Ricardo. 1959. Blest Gana y la novela realista. Santiago de Chile: Ediciones de los Anales de la Universidad de Chile. . 1942. "Las ideas del movimiento literario de 1842”. Atenea, Año XIX, № 203: 149192. 
Mac-Clure, Óscar. 2012. “Clases medias chilenas y transgresión de la homogamia: una perspectiva histórica. Universum, $\mathrm{N}^{\circ}$ 27: 111-141.

Martínez Bonati, Félix. $\quad$ 2004. El Quijote y la poética de la novela. Santiago de Chile: Editorial Universitaria.

Melfi, Domingo. 1938. Estudios de literatura chilena. Santiago de Chile: Nascimento.

Merino Reyes, Luis. 1959. Panorama de la literatura chilena. Washington, D. C.: Unión Panamericana.

Muñoz, Luis; Oelker, Dieter. 1993. Diccionario de movimientos y grupos literarios chilenos. Concepción: Ediciones Universidad de Concepción.

Oelker, Dieter. 1996. "La teoría de la vanidad en la obra novelesca de Luis Orrego Luco". Atenea 474: 67-91.

Orrego Luco, Luis. 1986. Pandereta (España). Santiago de Chile: Imprenta Cervantes.

Oviedo, José Miguel. 1997. Historia de la literatura hispanoamericana. Tomo 2: Del Romanticismo al Modernismo. Madrid: Alianza Universidad Textos.

Poblete, Juan. 2003. Literatura chilena del siglo XIX: entre públicos lectores y figuras autoriales. Santiago de Chile: Editorial Cuarto Propio.

Ricoeur, Paul. 1989. Ideología y utopía. Barcelona: Editorial Gedisa.

Román-Lagunas, Jorge. 1980. "Bibliografía anotada de y sobre Alberto Blest Gana". Revista Iberoamericana XLVI. 112-113: 605-647.

Salazar, Gabriel. 2007. Construcción de Estado en Chile (1800-1837). Democracia de los "pueblos". Militarismo ciudadano. Golpismo oligárquico. Santiago de Chile: Editorial Sudamericana.

Salinas, René. 2006. "La pareja: comportamientos, afectos, sentimientos y pasiones". Historia de la vida privada en Chile. El Chile moderno de 1840 a 1925. Rafael Sagredo y Cristián Gazmuri (dir.). Santiago de Chile: Taurus. 59-83.

Silva Castro, Raúl. 1941. Alberto Blest Gana (1830-1920). Estudio biográfico y crítico. Santiago de Chile: Imprenta Universitaria, 1941.

Panorama de la novela chilena. 1955. Ciudad de México: Fondo de Cultura Económica.

Sommer, Doris. 2004. Ficciones fundacionales. Las novelas nacionales en América Latina. Colombia: Fondo de Cultura Económica.

Vilches, Patricia. 2010. “Martín Rivas, Maquiavelo y la masculinidad decimonónica chilena”. Anales de Literatura Chilena, 13 (año 11), pp. 69-88. 
